\title{
Você acha que Disney é coisa para criança? Reveja isso já!
}

Era uma vez um menino norte-americano de família pobre. Sonhava ser ilustrador e pensava que, se você podia sonhar, podia realizar. Direto ao ponto, deu certo. Fundou em 1923 a Walt Disney Company, tão grande e com tantas outras empresas hoje, que é difícil descrever seu valor financeiro.

0 talento de Disney para os negócios era bom, mas não tanto quanto seu talento artístico. 0 homem, de fato, era um gênio na teoria das cores, do estudo dos movimentos e das figuras - humanas ou não. Compreendia a alma humana, suas ilusões e desatinos como poucos. Soube registrar essas impressões em suas personagens de forma marcante - tão impactante que já duram quase 100 anos.

Não poderia ser menos no que se refere à produção dos trajes de cena dos seus desenhos animados, curtas e longas-metragens. Branca de Neve e os sete anões, o primeiro longa da Disney, foi lançado em 1938. De pronto já ganhou um Oscar Honorário - junto com sete mini-Oscars, um para cada anão.

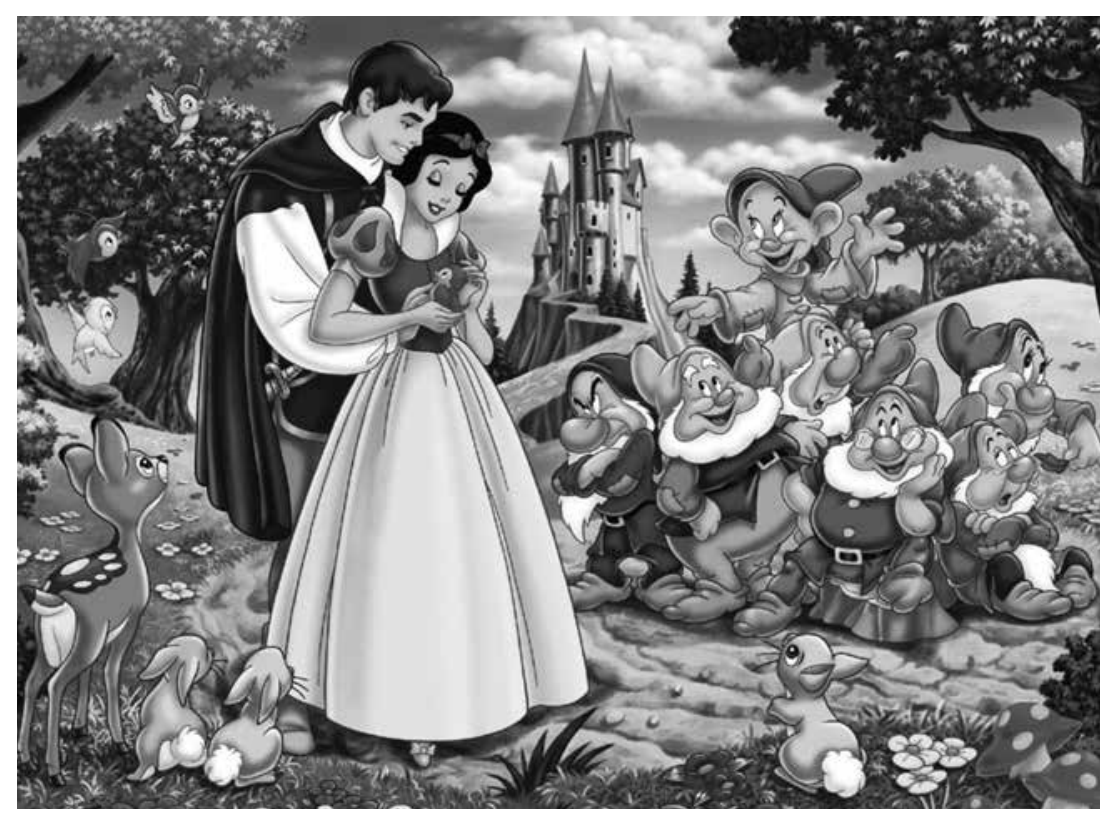

Branca de Neve e os sete anões (1938).

A "pobre princesa maltratada" Branca de Neve anda em trapos, servindo no castelo de sua madrasta bruxa, cantando romanticamente Someday my Prince will come. A inspiração das roupas é visivelmente medieval, evocando grandes aventuras românticas, damas e cavalheiros de torneios, da corte ou mundanos. Na edição comemorativa de 2009 de Branca de Neve, há um documentário chamado A Disney através das décadas, que mostra como foi o processo de criação e movimentação dos trajes.

Disney contratou pessoas para vestirem trajes parecidos com os que haviam sido projetados para os anões, por exemplo. Um dos pontos altos do vídeo - na opinião de 
uma pessoa que é louca por trajes - é quando se vê um homem dançando, um desenhista comentando: "Nossa, vê como a calça chega depois que ele bate o pé no chão?" e, já no filme, o anão dançando, com foco na calça.

Esse é apenas um exemplo do investimento altíssimo feito por Disney. Todos sabiam e 0 acusavam de ser louco por isso. Cada personalidade foi amplamente descrita e desenhada. Se Branca de Neve é uma princesa linda, branca, magra e ainda por cima canta lindamente, seu encontro com o príncipe mostra uma espera infantil por um homem que vai salvar sua vida, tirando-a daquela existência miserável e levando-a para um castelo onde ela seria rainha. Pior: felizes para sempre. Já sabemos do estrago que isso fez na cabeça de milhões de jovenzinhas (e outras nem tanto) pelo mundo. Mas se pensarmos naquele príncipe, sua participação é pequena, etérea, surge como um reflexo no poço d'água, canta um dueto de amor e... Some! Volta no final para salvar a donzela, com um beijo de amor verdadeiro. Não fosse o seu vozeirão, teria sua masculinidade questionada - é bastante delicado, delgado, com lábios sensuais avermelhados, perfeitos para uma... princesa.

Da mulher que espera um homem romântico passamos para a mulher que espera um romântico e sábio, também para viverem felizes para sempre. Esse é o sonho da amaldiçoada A Bela Adormecida (1959), também inspirada em conto dos Irmãos Grimm, como Branca de Neve. A fórmula "coitada de mim, bruxa malvada, príncipe encantado e beijo de amor" se repete. A qualidade técnica, no entanto, dá um salto, melhorando efeitos como a movimentação da capa da bruxa da Branca de Neve, que deixou de se deslocar "em bloco" para ter um movimento orgânico. Qual o príncipe que a princesa espera? Veja a cena de Aurora cantando no bosque com os bichinhos - quem faz a cabeça do boneco que representa o príncipe? Uma coruja, símbolo de sabedoria em várias culturas. Mas perceba a capa que o "boneco" veste - é vermelha! Como todo herói romântico deveria ter (menos o príncipe "pastel" da

Branca de Neve, que usa marrom). "Sabe, nós já nos encontramos em um sonho... Foi você o sonho boni-

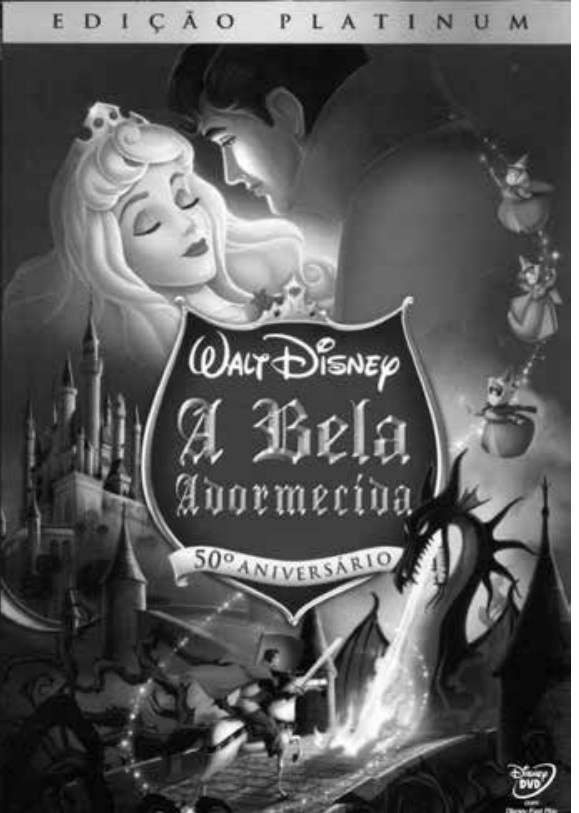

Capa do DVD da Disney de A Bela Adormecida.

0 romantismo revela-se na capa vermelha e no vestido rosa. to que eu sonhei... E o meu amor nasceu então!"

Mudou o mundo, mudou a Disney! Encantada (2007) mistura de desenho animado com filme normal, retrata uma princesa que constrói um príncipe com bichinhos, mas... Ele não é o príncipe com quem ela pensa que vai se casar, afinal já se conhecem há um dia inteiro (sic)! A Bruxa Má, a impagável Susan Sarandon, em uma roupa de couro muito fashion, a amaldiçoa no mundo encantado e a envia para um lugar real aonde ela nunca chegará a um final feliz - Nova York. A Disney satiriza tudo de amor que ela mesma plantou em décadas. 0 Príncipe de Andalasia (o mundo encantado) é lindo, com corpo excepcional (e o

figurino dele era estofado nos ombros, peitorais e nádegas, para aumentar o tamanho do excelente ator James Marsden, de Hairspray), canta lindamente, monta a cavalo... mas é fútil, vaidoso, depende apenas dele mesmo para ser feliz.

Há referências satíricas a pelo menos oito filmes da Disney. A princesa, Giselle, vai se apaixonar por um príncipe do mundo real - representado pelo ator Patrick Dempsey, talvez mais charmoso que belo. Ele é mal-humorado, usa apenas uma roupa preta o tempo todo, é grouchy, resmungão e ainda por cima foi abandonado pela mulher e cria a filha deles sozinho. Enrola uma namorada há cinco anos para casar e... se apaixona por Giselle, que veste florais e mangas bufantes. Que perfil de príncipe é esse? Um príncipe de verdade, que pode existir, ora

E então aconteceu... Frozen! 
Como disse o editor do sítio eletrônico Tyranny of Style , Joe Kucharski, "quando se pensa em um filme de animação da Disney, uma criação de trajes de cena espetacular pode não ser a primeira ideia que vem à mente".

Tudo isso mudou, segundo ele, em função dos trajes do filme: "Os trajes das personagens principais captam um sentido real de profundidade e credibilidade que é absolutamente notável para o gênero", complementando que o diretor de arte de Frozen, Mike Giaimo, descreve o filme como "o melhor figurino de filme animado CG (computer generated) até hoje".

Quem socorreu Giaimo foi a designer Jean Gillmore, que con-

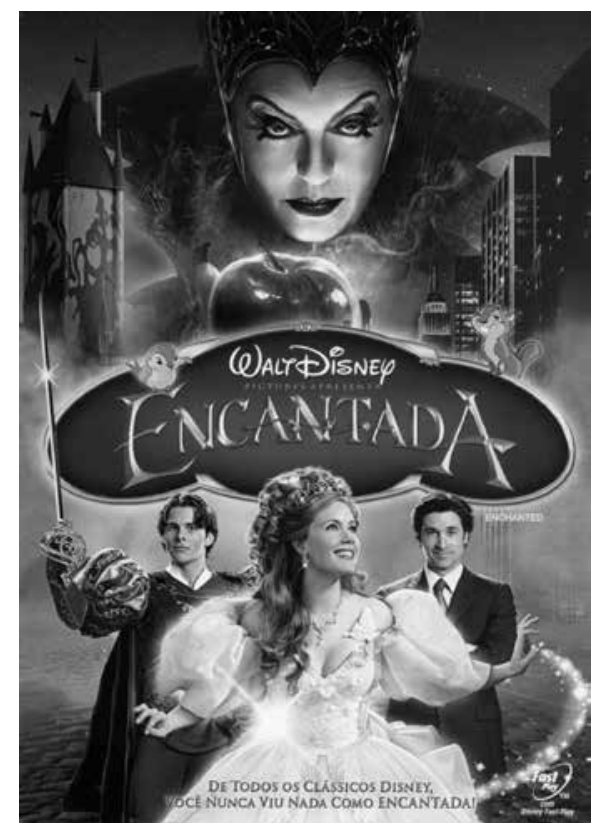

Amy Adams e Patrick Dempsey em Encantada.

Claro que o vestido dela foi feito a partir da cortina do apartamento dele.

tou que: "A animação 'tradicional' lidava com o design do traje de cena como uma parte integral do gráfico do desenho (cartoon), e não havia nenhuma distinção. (...) Mas com a animação CG, como tudo nela é construído/manipulado no computador, o traje tem que ter mais lógica nele - tem que ser mais real, ou se torna uma distração à ação da personagem virtual".

Ela conta também que entrou no filme porque o diretor de arte sabia de seu interesse por trajes históricos e que ela seria a colaboradora perfeita nesse conto de fadas da Disney. Se os trajes antes eram simplificados em estilo e período em função do foco nas linhas de fluidez no desenho da personagem, em Frozen eles mudam: a animação 3D/CG deixou disponivel um nivel de detalhe que nunca foi tentado antes, ela declarou.

E ainda que compôs os trajes por meio de pesquisa on-line (de imagem e texto), pois o di retor de arte sabia as cores que queria e que os trajes eram algo escandinavo e com um nível de detalhamento "tão alto quanto pudesse ser atingido dentro dos limites da razão". Ela visitou o mundo real de Solvang, Noruega, e fez fotos do lugar e de peças de traje que encontrou.

Minha abordagem geral foi fundir as silhuetas históricas dos trajes de 1840 da Europa Ocidental, com os formatos e relações de trajes e detaIhes dos trajes populares do início da Noruega, circa século dezenove. Peças como o chapéu de viagem de Anna são feitas a partir da intuição de Mike para os "trajes fofos" de Anna, e da minha simplificação de um chapéu norueguês verdadeiro, regional. Elsa: o vestido da Rainha da Neve era para ser de cristais de gelo simulados, flocos de neve e superfícies reflexivas comuns ao gelo nas suas diversas formas. Kristof, o coletor de gelo, tem roupas muito mais rústicas, de estilo e materiais mais primitivos. Os trolls, claro, tinham roupas nada refinadas, feitas a partir do material que estavam à sua volta. Em dado momento, juntei algumas imagens dos formatos gráficos, translúcidos, típicos dos desfiles de Dior, pensando que isso talvez ajudasse Mike a articular com o time parte do formato da sua linguagem para o filme todo. E ajudou.

Mais uma vez, a Disney dá uma virada nas personagens. 0 príncipe, da linha "delgado", é um vilão. A história de amor fica para a irmã da rainha, que não deixa de ser princesa - mas seu amor é por um plebeu, órfão de pai e mãe, cortador de gelo! A rainha, a suposta heroína da história, opta por viver só, sem príncipe no seu pé.

São tempos modernos, em que as pessoas permanecem juntas por vínculos (não só afetivos) reais, e não por obrigações estabelecidas pela sociedade. A cena de libertação da rainha, sob a música que ganhou o Oscar de melhor canção, Let it go, é a melhor demonstração do que um traje pode fazer por uma cena - ela tira o traje real, pesado, lutuoso, roxo e formal e solta os cabelos, vestindo uma roupa azul leve, diáfana.

É, poderia ser um Dior. 


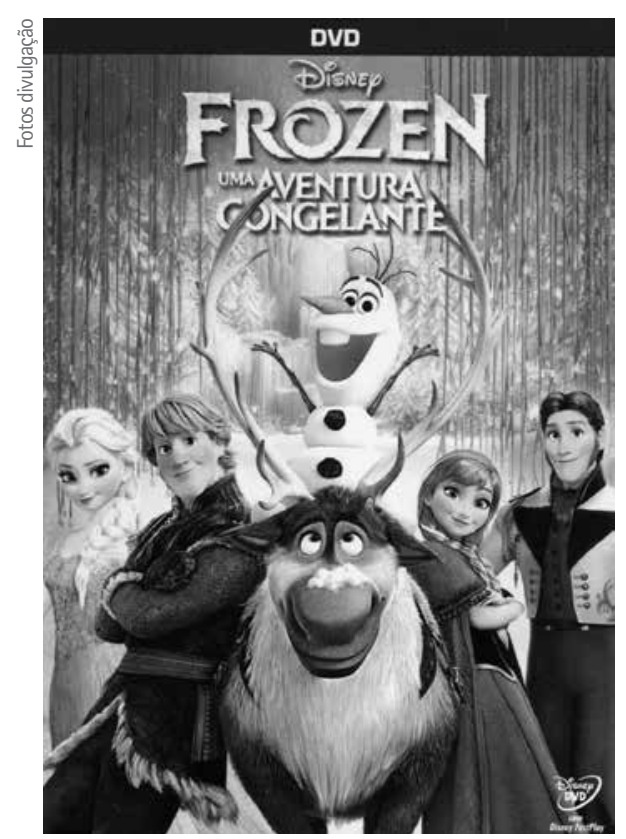

Arrecadações (ou se nada tocou seu coração)

Os dados (aproximados) são em dólares e somente para os Estados Unidos.

A fonte é Box Office Mojo, uma empresa da Amazon.com?.

A Bela Adormecida: 51,6 milhões

Branca de Neve: 185 milhões

Encantada: 127 milhões

Frozen: 400 milhões

\section{VIDEOGRAFIA}

A Bela Adormecida. DVD Edição comemorativa Platinum de 50 anos, Disney, 2008.

Branca de Neve e os sete anões. DVD Edição Comemorativa Diamante, Disney, 2009.

Encantada. DVD Disney, 2008.

Frozen. DVD Disney, 2014.

\section{QUER OUVIR E CHORAR?}

A Bela Adormecida (Uma vez num sonho). Disponível em:<http://www.youtube.com/ watch?v=YsV08EOjllk $>$. Acesso em 10 jun. 2014.

Branca de Neve e os sete anões (Sonhando assim). Disponivel em: <http://www.youtube.com/ watch?v=TVOCDB2lufE $>$. Acesso em 10 jun. 2014.

Encantada (Respectivamente, So close, música do baile final; e Como ela sabe que o ama? Cena do parque). Disponivel em: <http://www.youtube.com/watch?v=7ZUs4SaPXkU>. Acesso em 10 jun. 2014.

Frozen (Let itgo, Melhor canção, Oscar 2014). Disponivel em: <http://www.youtube.com/ watch? $v=$ moSFlvxnbgk $>$. Acesso em 10 jun. 2014.

\section{QUER SABER MAIS?}

SOLOMON, Charles. The art of Frozen. New York: Chronicle Books, 2013.

SMITH, David. The first 100 years. New York: Disney, 1999. 